\title{
افنساحسبة العـدـد
}

\section{قوي التفيير الأربعة العالية الأساسية

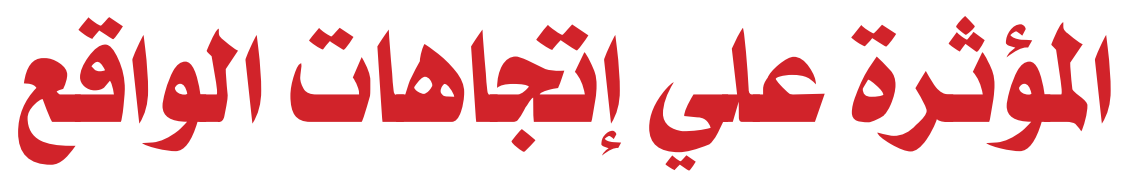

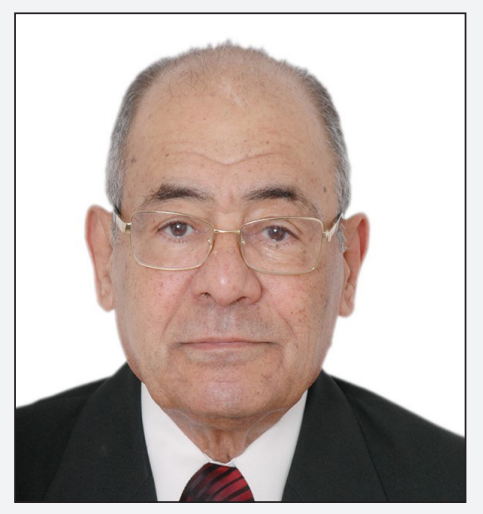

أ.د. محمد محمد الـهادي رئيس مجلس إدارة المجلة

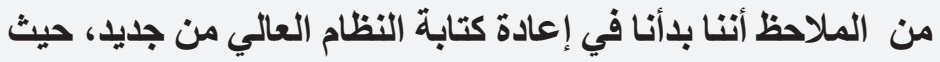

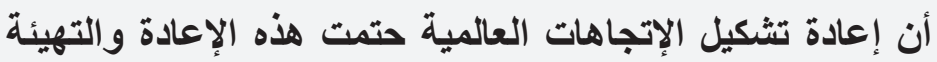

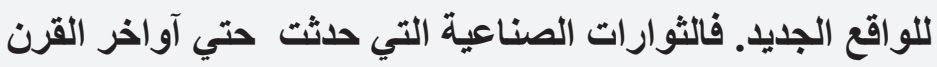

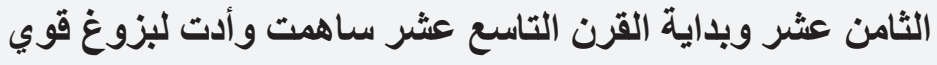

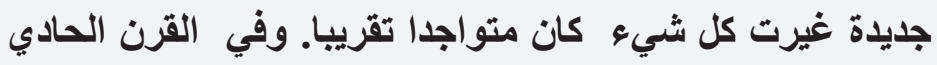

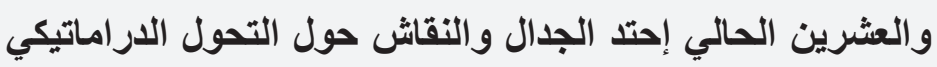

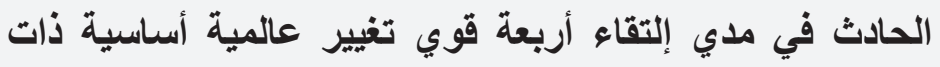

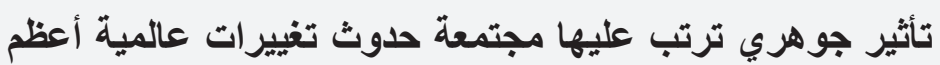

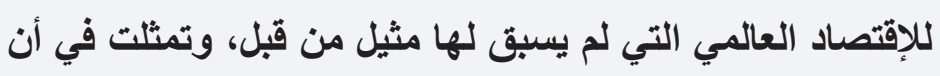

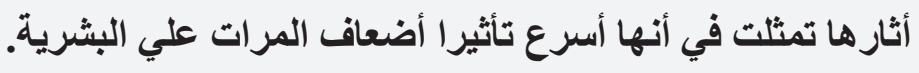

في القرن الحادي و العشرين الحالي يمكننا ملاحظة

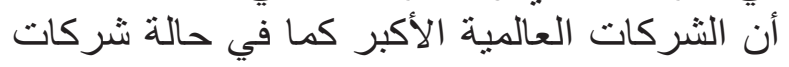

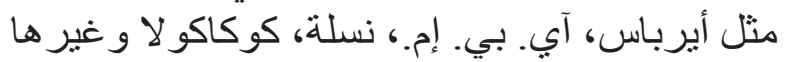

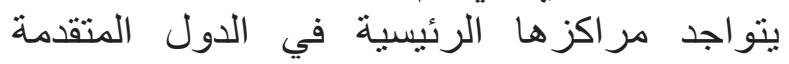

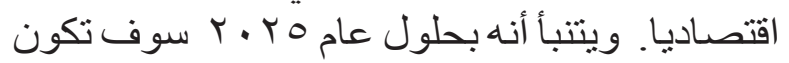

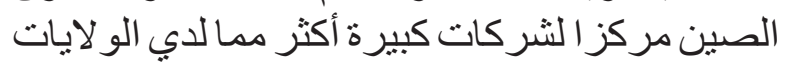

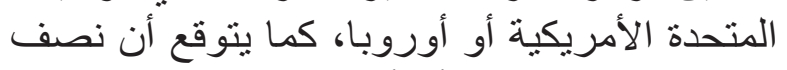

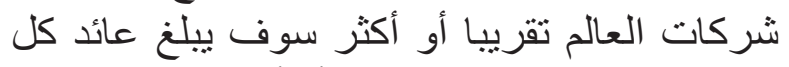

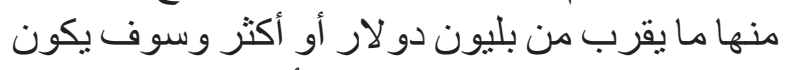
المركز الرئيس لكل منها في أسواق نامية دئ حديثا. وربما بنفس القدر من الأهمية سوف يتحول

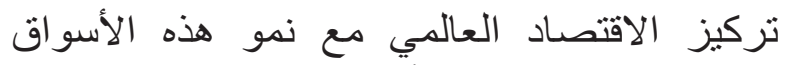
النامية. ومن الملاحظ أن سكان المدن العادئ الحضرية العالمية إرتفع بمتوسط وصل لحو لموالي 07

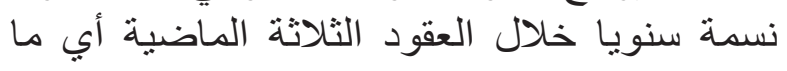
يعادل إضافة ما يقرب من سبع مدن مثل مدبنة
و علي الر غم من معرفتنا بحدوث هذه المتغير ات

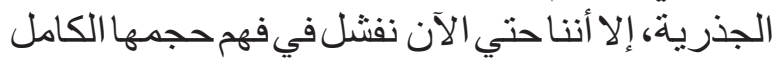

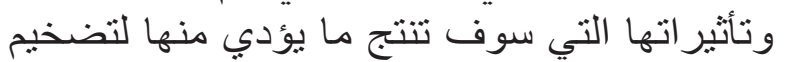
الآثار الناتجة من بعضها. هذه الإتجاهات التهات العالمية الحديثة صسارت تكتسب كل من القوة، الحجم و التأثير

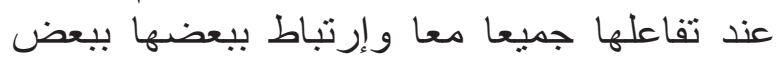
في التغيير و التأثير اللحظي الحادث منها مجتمعة. وفيما يلي إستعر اض لقوي التغيير العالمية الأساسية الأربعة المؤثرة علي إتجاهات الواقع الوفيل أولا: عصر التحضر: القوة الأساسية الأولي تمثلات حول تركيز النشاط الاقتصادي وديناميكة الأسو اق النامية كما في الصين الصين وفي كثير من مدن العالم المتقدم. هذه الأسو اق النامية

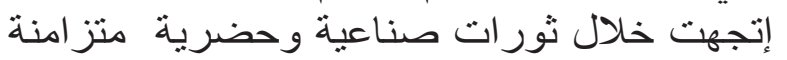

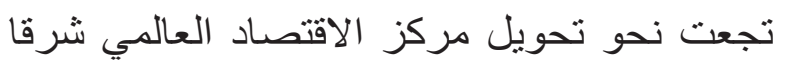
وجنوبا بسر عة لم تشاهد مثيل لها من قبل. وحديثا 
مرحلتها الأولي ما يقرب من سبعة ملايين نسمة

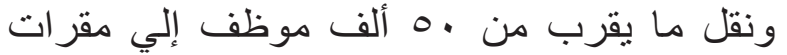
الوزارات بالحي الحكومي بها، ومدينة العالمين العين

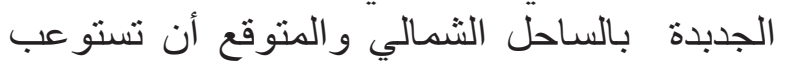

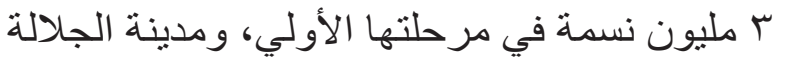
العالمية كمنتجع سياحي بين البحر الأحمر و الجبل، و غير ذلك من المشروعات العمر انية القائمة حليا.

\section{ثانيا: تسريع التغيير التكنولوجي:}

قوي التغيير العالمية الثانية تتمثل في تسريع مجال، وزن، وتأثثر التكنولوجيا الاقتصادي. حيث التئي أن التكنولوجيات من طباعة الصحيفة إلي آلة آلة البخار و الإنترنت كانت دائما قوي عالمية التية عظيمة التية في إنقلاب وتغيير الأوضاع العتان العالمية التي كانت

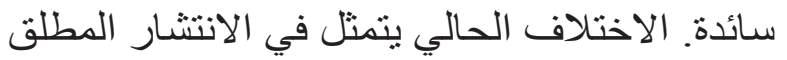
للتكنولوجيا في حياتنا وسر عة التافي التغيير الناتج منها.

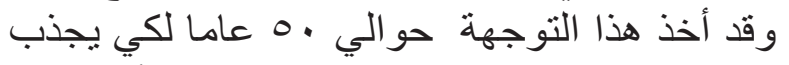

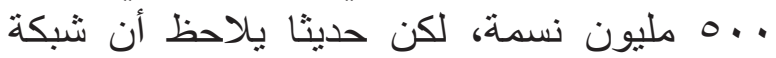

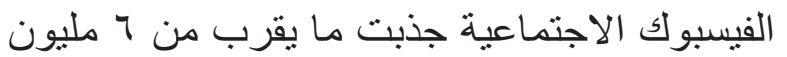

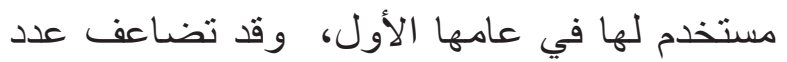

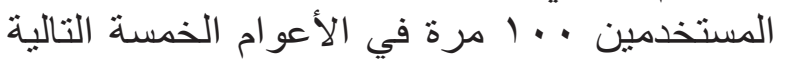

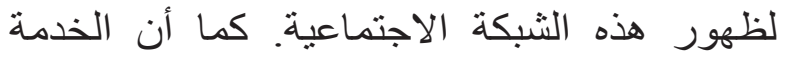

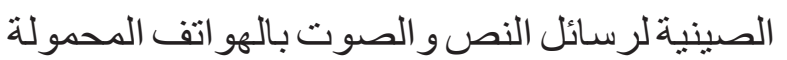
WeChat مستخدم أكثر من كل السكان البالغين في الولائات

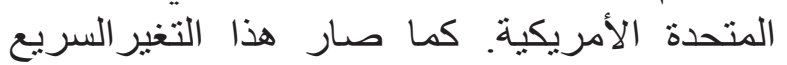
للتكنولوجيا يدعو للإبداع المنسارة المتسارع أيضا. وفي عام 9 + . ب أي بعد عامين فقط من إطلاق

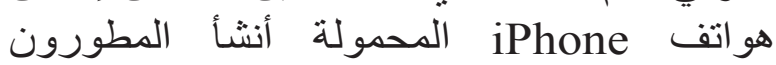

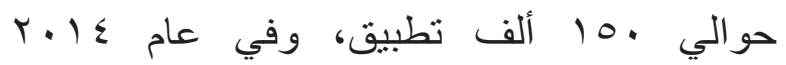
زاد عدد التطبيقات لحوالي مليون ومائتي ألف الف الن

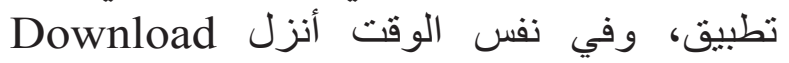

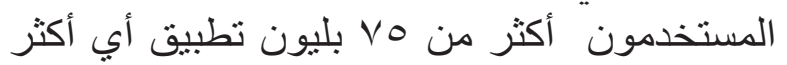

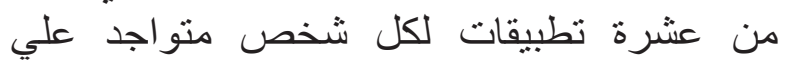
الكرة الأرضية. وقد نم كل هذا التطور من خلال

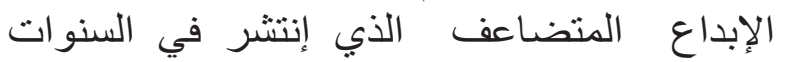

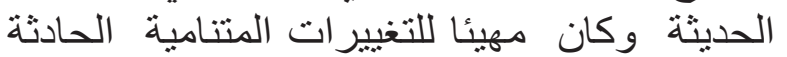
المصاحبة بلقوي الحدس البثرية للاستباق الحالية.
شيكاجو الأمريكية سنويا. كما أن تقريبا نصف نمو

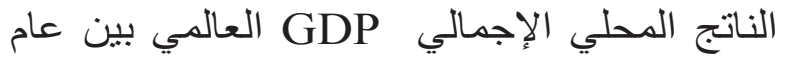

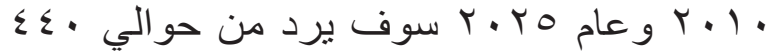

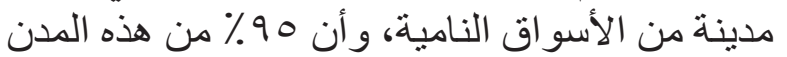

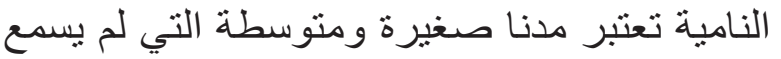

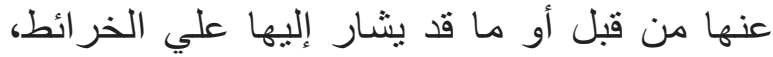

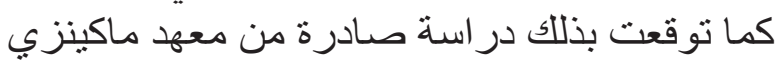

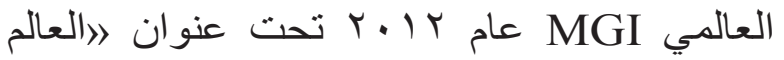
الحضري: المدن وصعود الطبقة المستهلكةها. وفي هذا السياق الحادث حديثا يتضح أن مدنا مثل

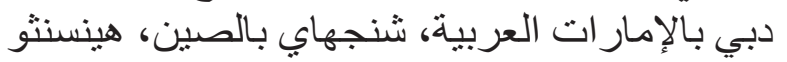

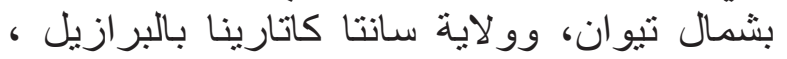

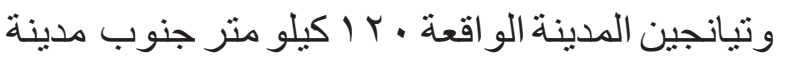
بكين الصينية تعتبر جميعها من أمثلة تلكئل الكينة المدن

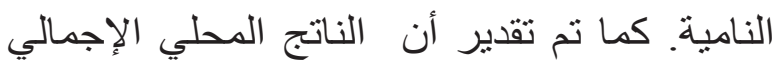

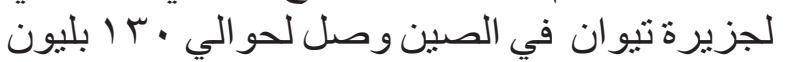

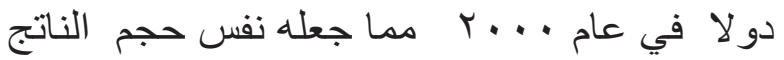
المحلي الإجمالي لمدينة استكهولم عاصمة المالم السويد

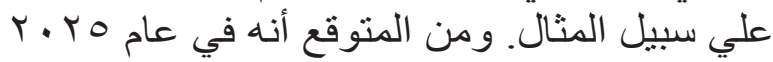
سوف يصل الناتج المحلي الإجمالي لمدينة تئن فيانجبن

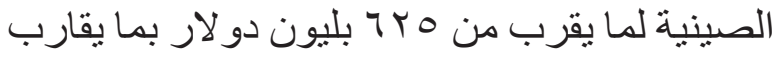
من نصف الناتج المحلي الإجمالي لدولة بلة مثل السويد. وفي حالة مصر التي قامت بالإسرع في إنشاء

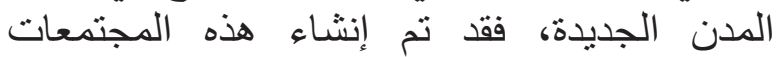

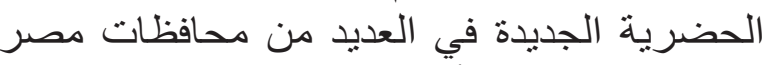

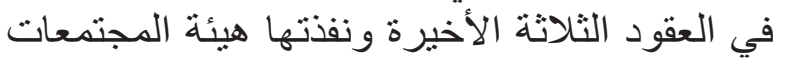
العمرانية حيث تم التخطيط والتنفذ لهذه التئة المدن علي أحدث النظم التخطيطية، وروعي في إن إقامتها

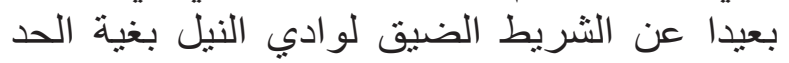

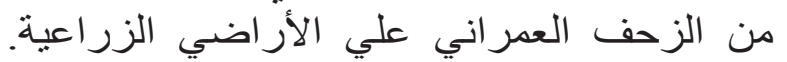

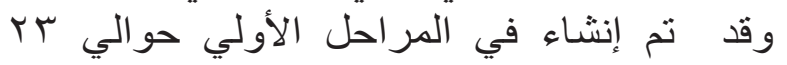

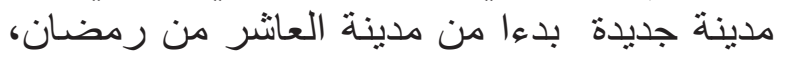

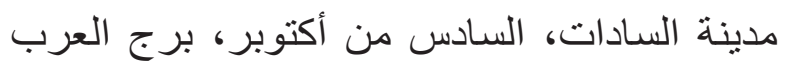

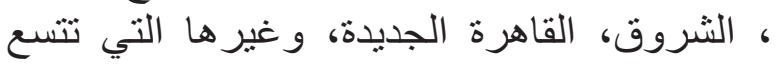

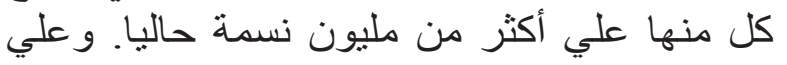
نفس النهج اضطلعت الدولة المصرية العدية حديثا بإنثاء

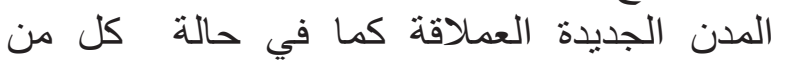

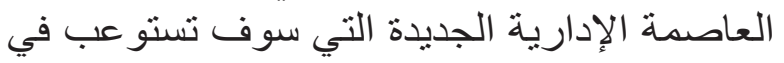




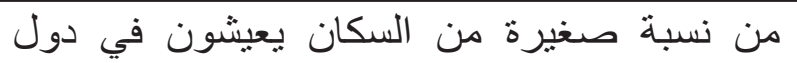

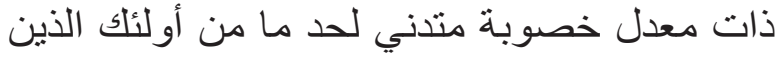

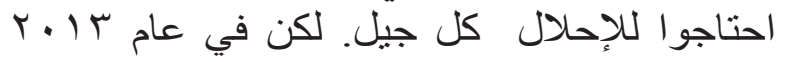

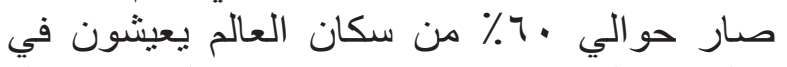

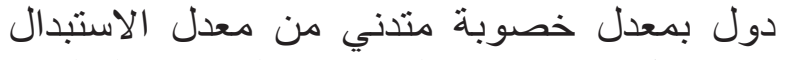
مما يمثل تغيير ا في التركيية السكانية العالمية.

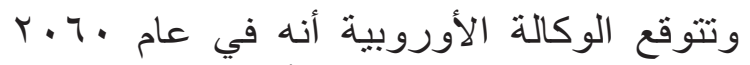

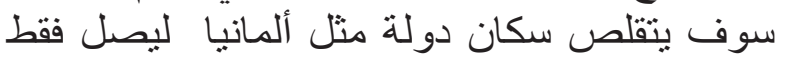

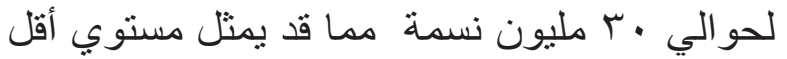

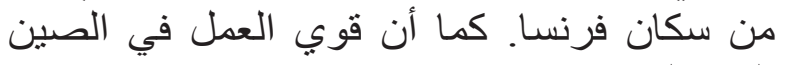

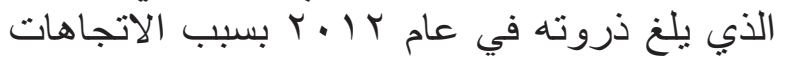

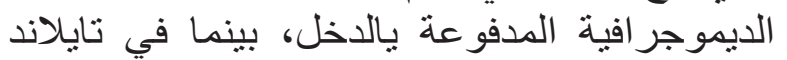

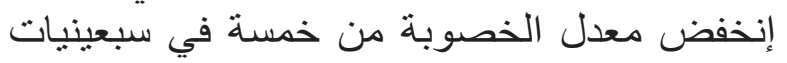
القرن العشرين الماضي إلي واحد وربع حاليا،

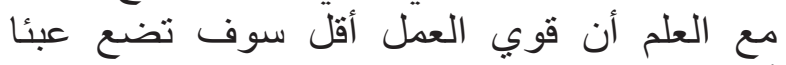

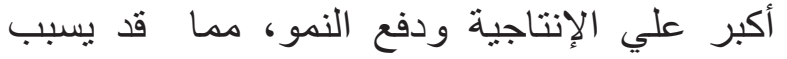

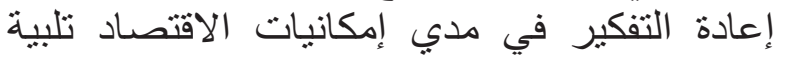

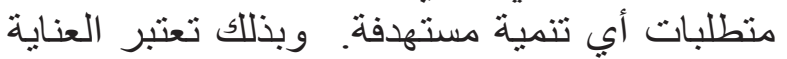

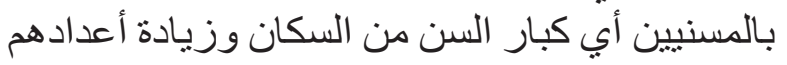

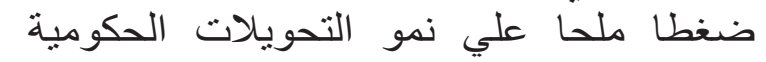

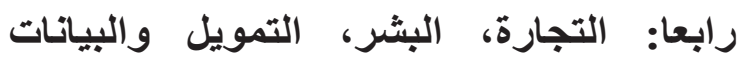
المرتبطة أعظم عالميا:

قوي إتجاهات التغيير الرابعة والأخيرة تتمثل في الدرجة التي سوف يكون عليت التيها العالم أكثر

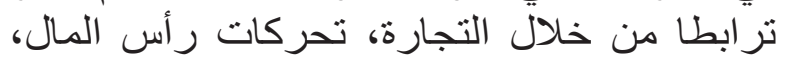

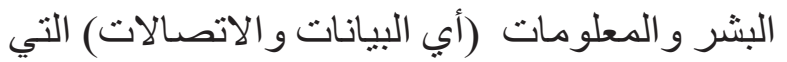
بطلق عليها التدفقات التجارية والتمويلية التية، اللتين التين

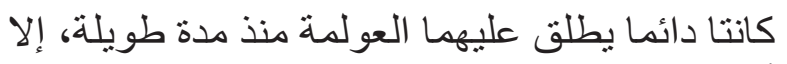

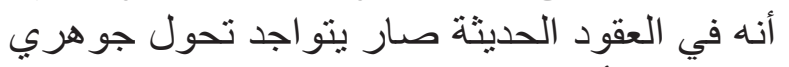

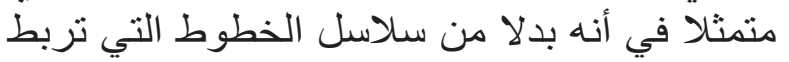
محاور تجارية رئيسية في أوروبا وشمال أنمال أُمريكا،

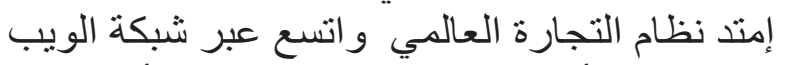

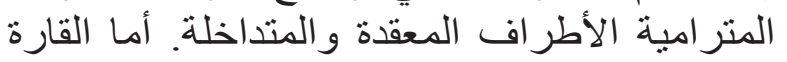

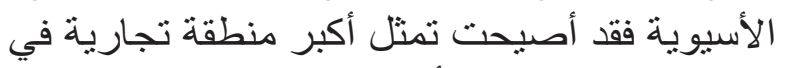

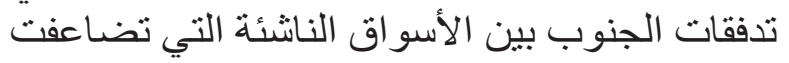

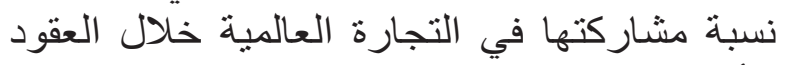

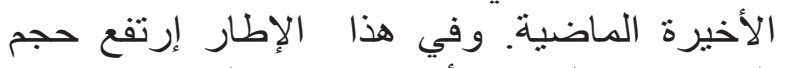

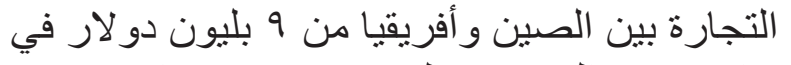

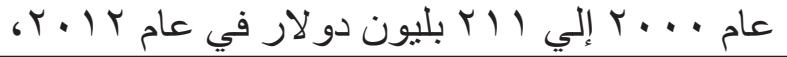

كما أن قوي المعالجة و التو اصل صارت تمثل

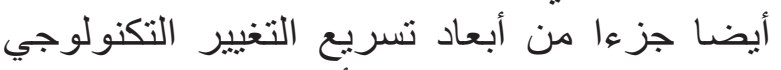
الحالي فقط فقط ؛ وساهم أيضا في مضادي الغناعفة هذا

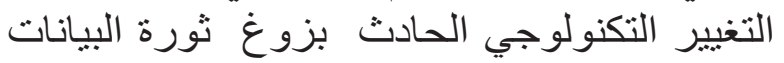

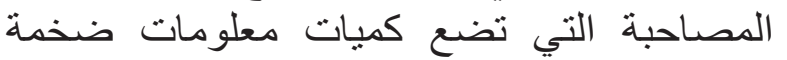
غير مسبوقة في أيدي المستهولكين والت والأعمال علي حد سواء؛ هذا إلي جانب إنتئ النتار نماذج

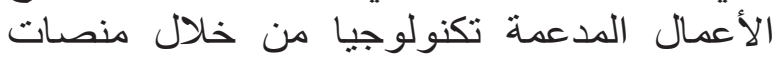

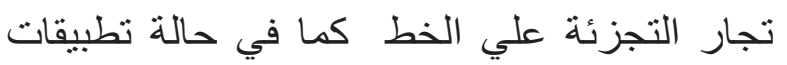
موقع علي بابا AliBaba الصيني إلي تطبيقات

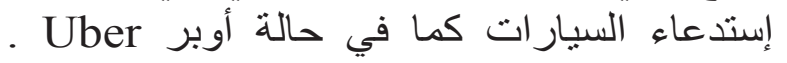

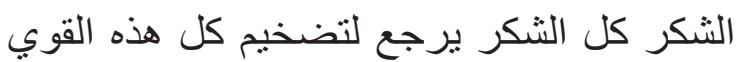
التكنولوجية بشكل متبادل مما أدي لاستفادة بشر الكتر أكثر

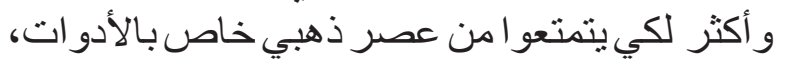

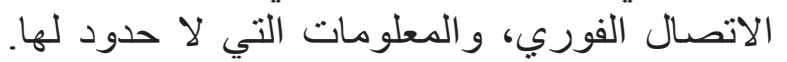

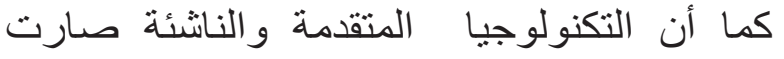

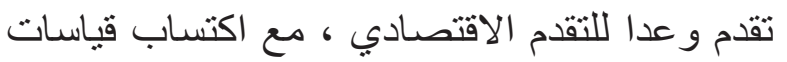

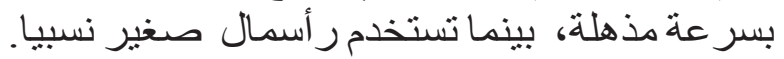

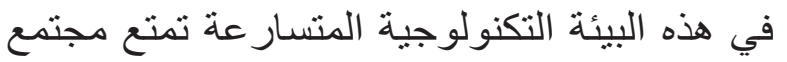

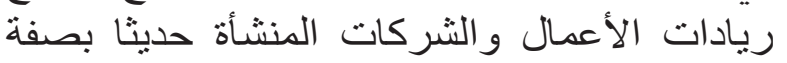

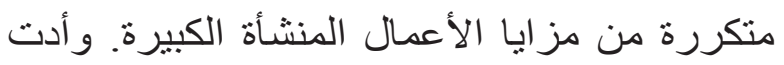

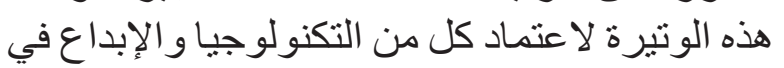

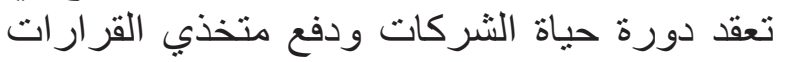

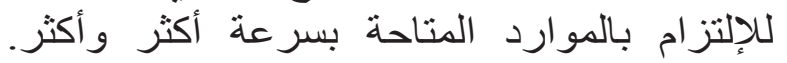

\section{ثالثا: قوي الاستجابة لتحديات عالم المسنين:}

هناك تنبؤات بأن عدد السكان في عالم المستقبل سوف يشتمل علي مسننين أكثر، كما أن فأن معدل الإل

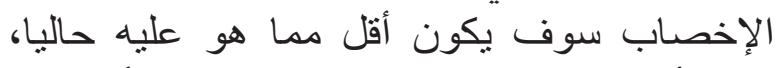
حيث أن سكلن العالم سوف يشيب بشكل أكبرن أكبر في

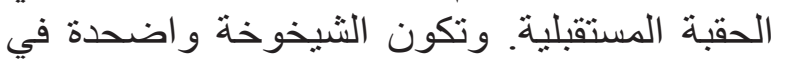
الاقتصاديات المتقدمة لبعض الونة الوقته، علي سبيل

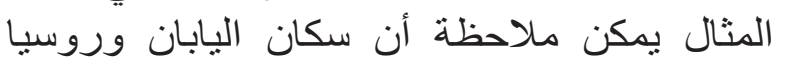

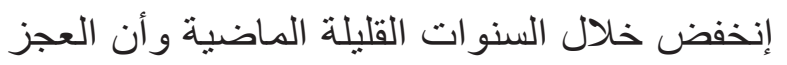

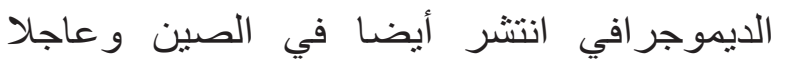

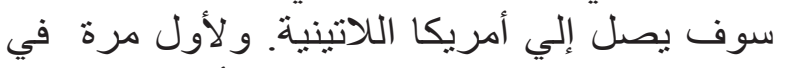

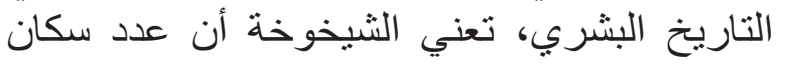

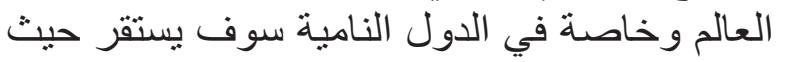

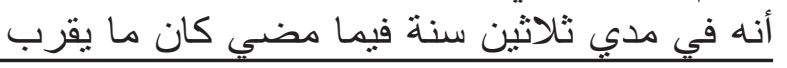




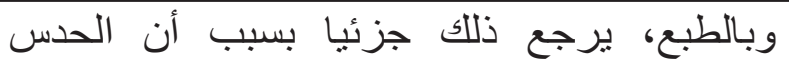
البشري ما زال يدعم عملية اتخاذ القرار كثيرا.

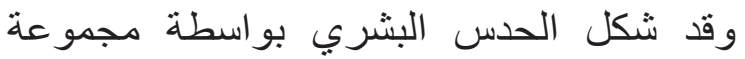
من الخبرات والآراء عن كيف تعمل الأن الأشياء خلال الوقت عندما تكون التغييرات توات تعاقبية ومتنبأ

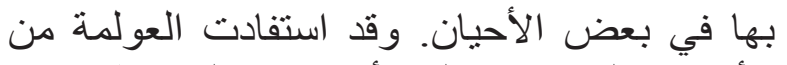
الأسواق المفتوحة، المنشأة جيدا والمان المرتبطة جيدا

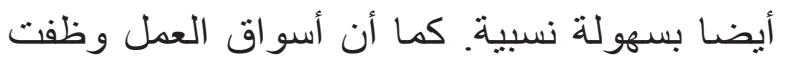

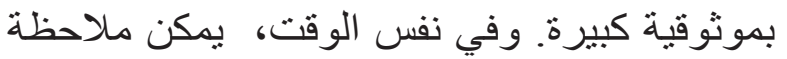

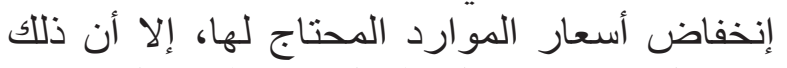
لا يمثل كيف يحتمل العمل في المستقبل. و وعند

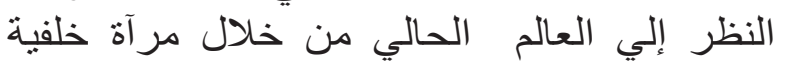

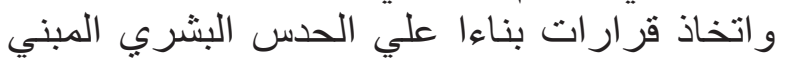

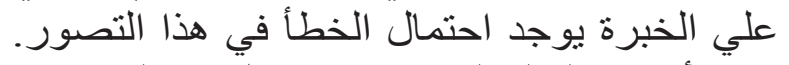

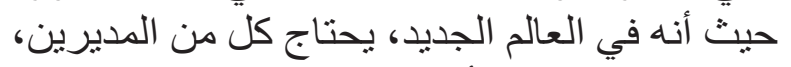

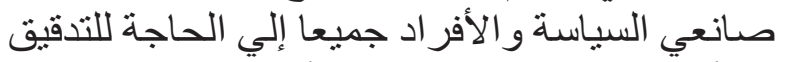

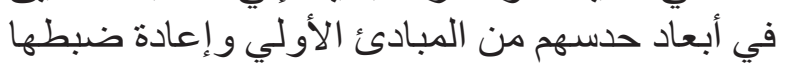
بجر أة متتاهية إذا لزم الأمر ذلكادئ ويمثل ذلإعلك حقيقة للمنظمات التي تمتعت بنجاح عظيم بصفة لاهن خاصة.

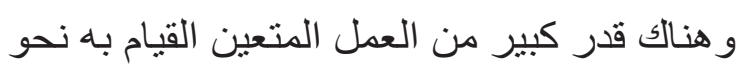

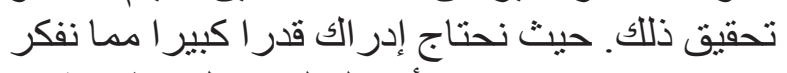

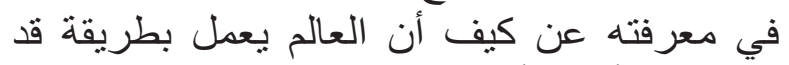

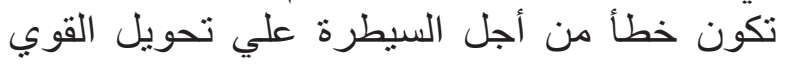
التخريبية للاقتصاد العالمي؛ ولتعريف التئي الاتجاهات

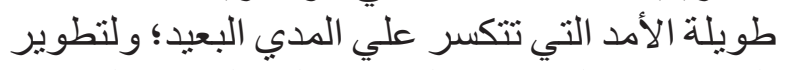

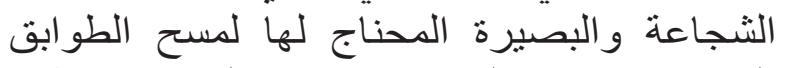

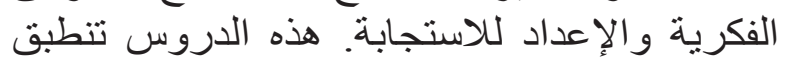

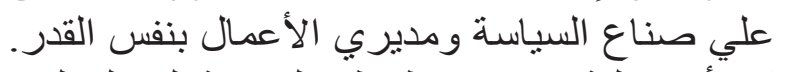

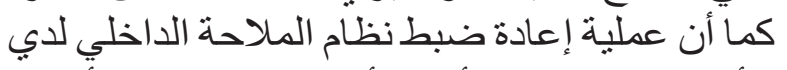
الأشخلص لا يمكن أن يبدأ بالسر عة الكافية أَيضاً.

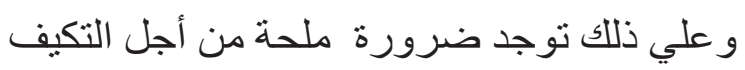

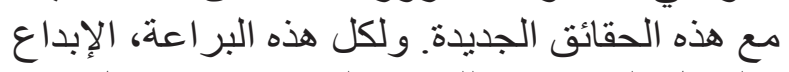

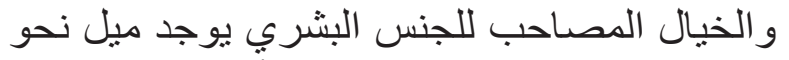

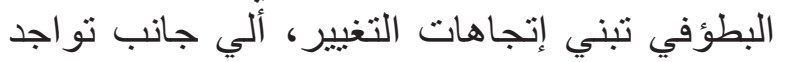

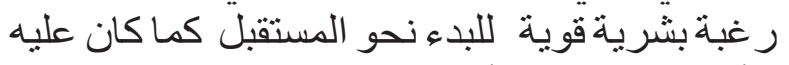

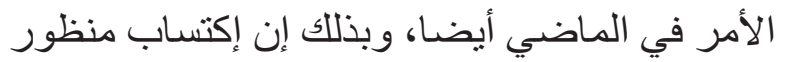

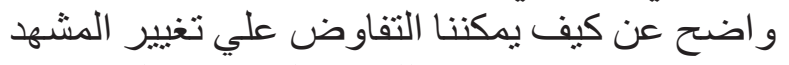
سوف يساعد في الإعداد للنجاح المستهدف لحد كبير.

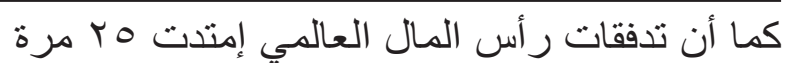

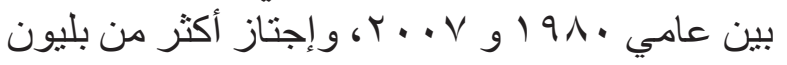

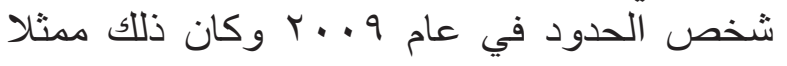
خمسة مرات العدد الذي كان عليه عام •،191.

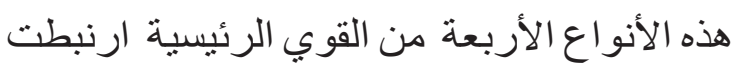

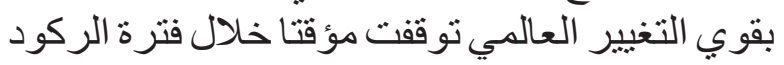

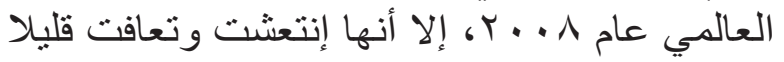
منذ ذلك الوقت، لكن الإرتباطات التي أقامتهات التهات

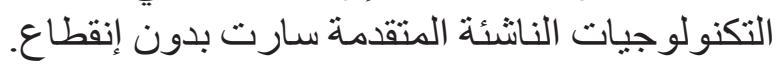
ومعزيادة سر عة التطوير الحادث فقد أذن ذللك بدخول

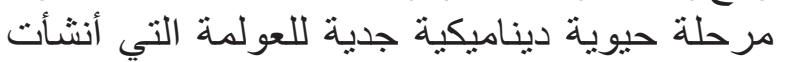

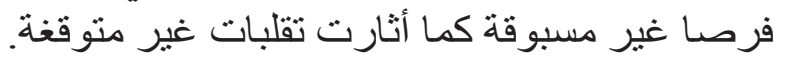

\section{الاستنتاج وإعادة الحسس:}

قوي التغيير العالمية الأربعة هذه جمعت وتيرة

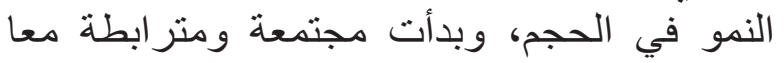

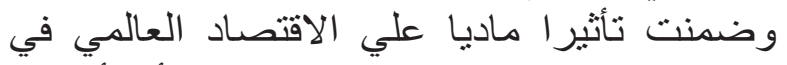
مطلع القرن الحادي والعشرين الحالي. أبي أنه في في الحي الحقبة الحالية صارت الحادي هذه القوي الأربعة مؤدية التهاية

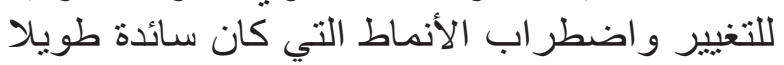

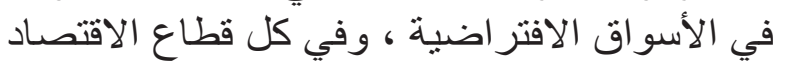
العالمي.، وكل جانب من حياتنا في الواقع ألع أيضا.

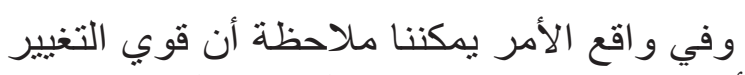

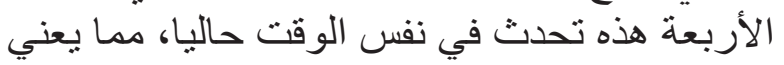

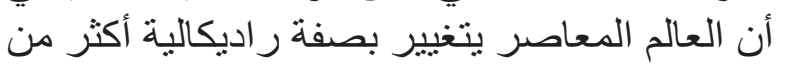

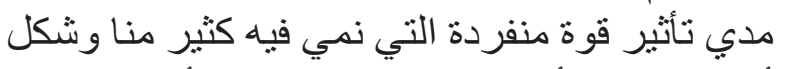

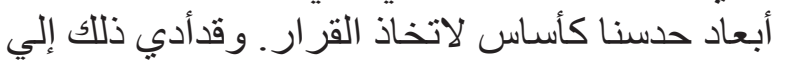

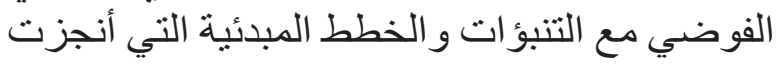
ببساطة من خلال استقراء التجربة التهاء الحديثة التي التئي

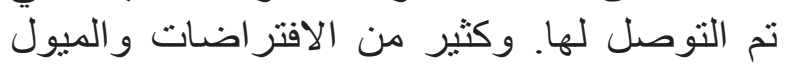

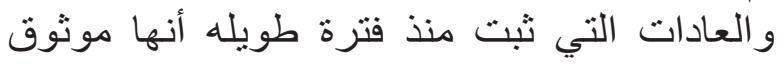

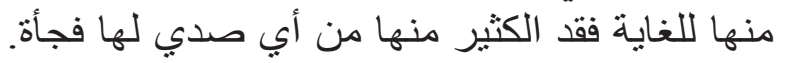

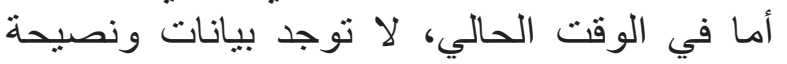

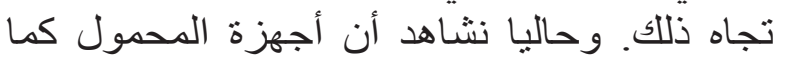
في حالة كل من تثتمل علي بيانات وقوة معالجة أكثر كثيرا من التها

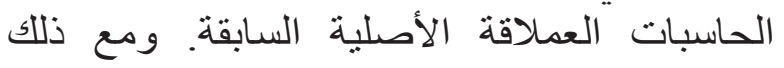
نعمل حاليا في عالم يكون فيه المتنبئين المهنيين غير مدركين لذلك بشكل خاص بطريقة فيلة روتينية. 